\title{
Paper 2: Coskewness in European Real Estate Equity Returns
}

Tobias Dechant

Chair of Real Estate Economics

IRE | BS International Real Estate Business School

University of Regensburg

Universitaetsstrasse 31

D-93053 Regensburg

Germany

Phone: +49 (0) 9419435064

Fax: +49 (0) 9419434314

e-mail: tobias.dechant@irebs.de

URL: www.irebs.de

Kai-Magnus Schulte

Chair of Real Estate Management

IRE | BS International Real Estate Business School

University of Regensburg

Universitaetsstrasse 31

D-93053 Regensburg

Germany

Phone: +49 (0) 9419435075

Fax: +49 (0) 9419435072

e-mail: kai-magnus.schulte@ irebs.de

URL: www.irebs.de 


\begin{abstract}
This paper investigates the effect of coskewness on expected European real estate equity returns. The study tests whether equities that contribute negatively to the skewness of the general equity market have, on average, higher returns than those which contribute positively to market skewness. In addition to the Fama-French $(1993,1996,1997)$ three-factor model, two multi-factor models as well as unconditional and conditional Fama-MacBeth (1973) cross-section regressions are applied to a sample of 275 real estate equities from 16 European countries over the 1988 to 2009 period. The results show that the inclusion of a quadratic market term does not yield incremental explanatory power over the Fama-French three-factor model in time-series regressions. When considering four different measures of coskewness, cross-section results reveal that coskewness is an important factor in explaining unconditional as well as conditional European real estate equity returns, independently of whether the conditioning variable is the general or the real estate equity market. However, results are dependent on the measure of coskewness employed and the examined time period. In accordance with other studies, a relationship between size and coskewness is evident.
\end{abstract}

Keywords: European Real Estate Equities, Asset Pricing, Coskewness, Fama-French, FamaMcBeth

Subject classification codes: G10, G11, G12, G15 


\subsection{Introduction}

The Capital Asset Pricing Model (CAPM) of Sharpe (1964) and Lintner (1965) relies on the strict assumption that asset returns follow a Gaussian normal distribution. However, most financial assets, including real estate equities, are not characterized by a normal distribution. A number of studies such as Myer and Webb (1993, 1994), Young and Graff (1995), Lizieri and Satchell (1997), Lu and Mei (1998), Bond and Patel (2003), Liow and Sim (2005), Young, Lee and Devaney (2006), Young (2008), Lee Robinson and Reed (2008), as well as Yang and Chen (2009) demonstrate that the density function of real estate returns does not exhibit normality, but often reveals significant skewness and fat tails. This makes the CAPM unlikely to hold, such that the measurement of systematic risk requires more than covariance with the market return. When returns are non-normally distributed, risk-averse investors, who are concerned about extreme portfolio returns, should account for higher-order comoments in their risk assessment. This paper, in particular, considers the role of systematic skewness, also referred to as coskewness, and its effect on expected real estate equity returns. Coskewness measures whether extreme positive or negative returns occur jointly with those of the market return. If investors hold the market portfolio, it is not the skewness of an individual security, but its contribution to market skewness that should matter in asset pricing. As investors should prefer assets that are right-skewed to those that are left-skewed, assets that decrease the skewness of the market portfolio should command higher expected returns. Depending on the skewness of the market, coskewness should evoke a positive or negative risk premium in cross-sectional regressions. Neglecting systematic skewness might therefore yield biased and irrational risk premiums, which in turn could result in erroneous risk assessments and investment decisions.

Although some research on higher-moment asset pricing has been conducted on the Asian and the US real estate markets, there is, to the authors' knowledge, no such study on European real estate equities. This paper contributes to the explanation of European real estate securities and builds on the results of Schulte, Dechant and Schaefers (2011). The study is the first to examine the effects of coskewness in European real estate equity markets. In particular, the pricing of 275 real estate equities from 16 European countries over the 1988 to 2009 period is investigated by performing Fama-French (1993, 1996, 1997) time-series and Fama-MacBeth (1973) cross-section regressions. The following research questions are addressed. Firstly, the study analyzes whether quadratic market factors are able to reduce the explanatory power of traditional factors such as the return on the general equity market and the Fama-French factors, SMB and HML in time-series regressions. Moreover, the investigation considers whether investors reward an unconditional risk premium for 
those real estate securities which contribute negatively to the skewness of the market portfolio and vice versa. Following Pettengill, Sundaram and Mathur (1995, 2002), the study further examines whether there is a conditional relationship between loadings on systematic risk factors and equity returns, i.e. whether coskewness can explain equity returns when an explicit distinction is drawn between up and down-market movements of the general or the real estate equity market in crosssectional regressions. The study contributes to the understanding of the barely investigated pricing of European real estate equities. It provides an empirical framework of how coskewness enters asset pricing, dependent on the state of the general equity and the real estate market. In practical terms, the study may help investors improve their risk assessment and to perform time-varying investment strategies.

The results show that the inclusion of a quadratic market term does not yield incremental explanatory power over the Fama-French three-factor model in time-series regressions. When considering four different measures of coskewness, the cross-section results reveal that coskewness is an important factor in explaining both unconditional and conditional European real estate equity returns, independently of whether the conditioning variable is the general or the real estate equity market. However, results are dependent on the specific measure of coskewness and the time period examined. In accordance with other studies, a relationship between size and coskewness is evident.

The remainder of the study is organized as follows. The next section reviews related studies on the role of higher moments, and especially coskewness, in general and real estate asset pricing. Section 2.3 provides a theoretical framework on how coskewness enters asset pricing. Section 2.4 describes the sample selection and portfolio formation process and presents descriptive statistics on the portfolios formed. Section 2.5 describes the coskewness measures and the asset pricing approach. The subsequent two sections present the results of the time-series and cross-section regressions, after which a set of robustness checks is performed. The final section concludes.

\subsection{Literature Review}

\subsubsection{The Role of Coskewness and Higher-Order Comoments in the Pricing of Risky Assets}

The foundations of multi-moment security pricing date back to Rubinstein (1973) and Ingersoll (1975). Kraus and Litzenberger (1976) are the first to advocate a three-moment asset pricing model, in which both covariance and coskewness explain the cross-sectional variations in expected asset returns. Their results support the theoretical implications which demand for the pricing of 
systematic skewness, and predict a zero-intercept for the security market line. Scott and Horvath (1980) develop a theoretical framework which shows that investors should prefer odd moments and have an aversion towards even moments. Friend and Westerfield (1980) examine a sample of US stocks between 1926 and 1973. They find some, but not conclusive evidence - their results are sensitive towards weighting effects, the market portfolio composition and individual or group returns - of the proposition that investors may be willing to pay a premium for positive skewness in their portfolios. They further conclude that the Kraus-Litzenberger finding of a zero intercept is likely to result from the specific nature of the analyzed period and the missing examination of sub periods. Since Friend and Westerfield estimate a risk-free rate of return which is significantly higher than the actual one, they consider the attempt of Kraus and Litzenberger rather unsuccessful. Barone-Adesi (1985) employs a quadratic market model for a sample of US equities throughout the 1926 to 1975 period. He provides some support for the Kraus-Litzenberger hypothesis on skewness preference, but concedes that econometric problems might affect his tests. Furthermore, he notes that the arbitrage equilibrium associated with the quadratic market model is not sufficient to describe security returns, so that further factors must be considered. Fang and Lai (1997) test US stocks over the 1969 to 1988 period. They investigate a four-moment CAPM and point out that in addition to systematic variance, cokurtosis is related to the excess returns of risky assets, as investors have to be compensated for bearing higher systematic risk measured by these factors. Although coskewness evokes the expected risk premium which has the opposite sign to that of the market portfolio's skewness, it is not significant within all examined subperiods. Hwang and Satchell (1999) find no significant relationship between emerging market returns and covariance, coskewness and cokurtosis over the 1985 to 1997 period. Nevertheless, their results show that asset pricing models which include higher moments can explain returns more accurately than the traditional CAPM. Harvey (2000) examines the effect of 18 different risk measures on the returns of 47 developed and emerging markets between 1988 and 1999. He finds that, in particular, world-market beta and world-market coskewness, but also variance and skewness, capture crosssectional returns reasonably well. Harvey and Siddique (2000) show that systematic skewness, proxied by the difference return between a portfolio of stocks that adds negative skewness to the market portfolio and the return on stocks which contribute positively to the skewness of the market portfolio, commands a positive and significant risk premium over the July 1963 to December 1993 period in the US equity market. They further demonstrate that conditional skewness helps explain the cross-sectional variation in equity returns. This effect remains significant, even when factors based on size and book-to-market equity are included. Their analysis also provides evidence that the momentum effect is related to systematic skewness. For each of their momentum definitions, 
low expected return momentum portfolios are found to have higher skewness than high expected return portfolios. Christie-David and Chaudry (2001) show that the second, third and fourth moments are fundamental in explaining the returns on 28 interest rate, commodity and currency futures from 1982 to 1996. The explanatory power of their model increases when higher comoments are included and the results remain robust to the use of nine different market proxies. Galagedera, Henry and Silvapulle (2003) estimate conditional cross-sectional regression in order to determine factor risk premiums on covariance, coskewness and cokurtosis for Australian equities in the 1985 to 2000 period. They find that beta evokes a positive risk premium in up markets and a negative one in down markets. Depending on the skewness of the market portfolio in up or down states, the authors find coskewness to be priced, while cokurtosis evokes insignificant risk premiums in most cases. Barone-Adesi, Gagliardini and Urga (2004) employ size-sorted Fama-French portfolios from 1963 to 2000 to estimate a quadratic market model, in which they find that coskewness risk evokes a significant premium. Furthermore, they argue that size and coskewness are correlated, as portfolios of small (large) firms exhibit negative (positive) coskewness with market returns. This, in turn, reasons the explanation for the empirically observed relationship between size and excess asset returns to result from the omission of a systematic risk factor. Hung, Shackleton and Xu (2004) perform a cubic market model and estimate (conditional) cross-section regressions for a sample of UK stock returns between 1979 and 1999. They find a strong explanatory power of beta in their conditional model, even when higher-order comoments and the Fama French factors are included. There is also some evidence of the explanatory power of higher-order comoments, which stems mostly from periods when stock markets perform badly. Chung, Johnson and Schill. (2006) show that systematic comoments - but not standard moments - up to order ten, reduce the explanatory power of the Fama French factors in daily, weekly, monthly, quarterly and semiannual cross-sectional regressions of US security returns during the 1930 to 1998 period. Nguyen and Puri (2009) further illustrate that not only the Fama French factors, but also momentum and liquidity factors, can be explained by higher-order comoments. The authors also demonstrate that standard moments cannot absorb the explanatory power of higher comoments. Their sample covers US stock returns from 1965 to 2005. Smith (2006) tests the conditional three-moment CAPM between 1963 and 1997 in the US and finds that coskewness is important in explaining the cross-section of asset returns. He finds strong evidence to support the argument that coskewness and the price of coskewness risk are both time-varying. Investors care more about coskewness risk when the market is positively skewed than when it is negatively skewed. When the market is positively skewed, investors are willing to sacrifice $7.87 \%$ per unit of standardized coskewness risk annually. However, when the market is negatively skewed, they only 
demand a premium of $1.80 \%$ annually. Galagedera and Brooks (2007) construct several measures of third-order comoments in a downside risk framework to explain cross-sectional variation in returns from 27 emerging markets from 1987 to 2004. They find that downside coskewness, measured as coskewness when the equity market performs below a pre-specified benchmark return, consistently generates a positive risk premium and is the dominant explanatory variable, even when other systematic risk measures are included in the pricing model. Hung (2007) analyses a sample of more than 11,000 companies from 19 countries over the 1987 to 2005 period. For sizesorted portfolios, he finds that the linear CAPM explains the time-series returns of large stocks well, while the squared market return deviation contributes significantly towards explaining the returns on the small-size stock portfolio. When stocks are sorted according to past winners and losers, the inclusion of the squared market return deviation significantly increases the explanatory power for winner portfolios and is negatively related to returns. The inclusion of a cubic market term does not add explanatory power to any of the considered models. In terms of return predictability, the higher moment CAPM does not outperform the linear CAPM, which is likely to be a result of parameter uncertainty on the quadratic and cubic market factor. Misirli and Alper (2009) employ a data base which comprises 318 equities traded on the Istanbul stock exchange from 1996 to 2005 . Their findings reveal that small-size portfolios contribute negatively to the skewness of the broader equity market. This implies that an asset-pricing model which lacks coskewness overestimates the risk premium related to size. This finding is also confirmed by crosssectional regressions, given that a significant contribution of coskewness to the traditional CAPM, in particular for size-sorted portfolios, is evident. However, coskewness proves to have no significant incremental explanatory power over the Fama-French factors, although it induces a decrease (albeit significant) in the pricing bias in time series regressions.

\subsubsection{Higher Moments in Real Estate Returns}

Although the effect of higher moments - in particular coskewness - is evident in the general asset pricing literature, its effect on real estate equities is not documented comprehensively.

Liu, Hartzell and Grissom (1992) are the first to test whether systematic skewness is priced in real estate returns. They employ quarterly appraisal-based data on five commingled real estate funds (CREFs) from 1979 to 1989 for a multivariate test of the Kraus-Litzenberger model. Their findings underpin the importance of skewness for assessing direct real estate risk. Direct property returns exhibit significant negative skewness, but the average coskewness parameter is found to be less negative than for stocks in general. Since the used market proxies are normally distributed, direct property can be considered as less risky than stocks, for which reason investors are generally 
willing to accept a lower level of expected return. These results hold not only for the KrausLitzenberger-CAPM, but also for the zero beta-CAPM and the consumption-based CAPM. The study of Vines, Hsieh and Hatem (1994) applies the three-moment CAPM of Kraus and Litzenberger to determine the impact of systematic variance and systematic skewness on the crosssection of equity REIT returns between 1975 and 1991. In contrast to Liu et al. (1992), they find that coskewness cannot explain cross-sectional return variations in any of their models, whereas the opposite holds for the classic CAPM beta. Cheng (2005) corresponds with these results, as he also finds that neither unconditional nor conditional coskewness, which is employed due to the strong autocorrelation in valuation-based data, can sufficiently explain cross-sectional NCREIF property returns. The same holds for the traditional CAPM beta. However, there is strong evidence that higher downside beta is associated with higher returns, while upside beta is not priced. Skewness also commands a significant risk premium, which remains in the presence of downside beta. Moreover, the significance of downside beta and skewness is independent of the property type examined. Liow and Chan (2005) examine the importance of coskewness and cokurtosis to explain a sample of 19 global real estate security indices from 1994 to 2004 . Their study provides some support that coskewness and cokurtosis are important risk measures in explaining crosssectional real estate security returns. The authors point to the importance of selecting an appropriate market portfolio and find that cokurtosis has more explanatory power than coskewness. Lee et al. (2008) analyze the ability of downside beta to price a sample of Australian Listed Property Trusts from 1993 to 2005. They also include skewness and coskewness in their cross-sectional regressions. The authors provide no evidence that skewness or coskewness can explain cross-sectional return variations, but demonstrate that cokurtosis reduces the explanatory power of downside beta. Yang and Chen (2009) employ (conditional) beta, coskewness and cokurtosis to explain monthly cross-sectional REIT returns from 1965 to 2007 . They find that systematic variance, as well as cokurtosis, plays a major role in the pricing of listed real estate assets, while coskewness is not significant in any of their models.

\subsection{Theoretical Framework ${ }^{1}$}

All investors $K$ are assumed to maximize their expected utility function, represented by an indirect utility function, denoted $V_{k}($.$) with k=[1, \ldots, K]$. It is concave and increasing with expected portfolio return and portfolio skewness, and concave and decreasing with portfolio variance.

\footnotetext{
${ }^{1}$ For a more detailed theoretical framework on higher moment asset pricing and higher moment asset allocation, please refer to Jurczenko and Maillet (2006).
} 
The expected utility function can be represented as

$$
\left\{E\left[U_{k}\left(R_{p}\right)\right]\right\}=V_{k}\left[E\left(R_{p}\right), \sigma^{2}\left(R_{p}\right), s^{3}\left(R_{p}\right)\right]
$$

With:

$$
V_{k}^{(1)}=\frac{\partial V_{k}(\cdot)}{\partial E\left(R_{p}\right)}>0, V_{k}^{(2)}=\frac{\partial V_{k}(\cdot)}{\partial \sigma^{2}\left(R_{p}\right)}<0, V_{k}^{(3)}=\frac{\partial V_{k}(.)}{\partial s^{3}\left(R_{p}\right)}>0
$$

where $R_{p}$ is the return of the portfolio held by investor $k, \sigma^{2}$ denotes portfolio variance and $s^{3}$ is portfolio skewness. Consider an investor who allocates part of his wealth, $w_{p i}$, to the $i$ th risky asset, $i=[1, \ldots, N]$ and $w_{r f}$, to the riskless asset. The mean, variance and skewness of the portfolio return are respectively given by:

$$
\begin{gathered}
E\left(R_{p}\right)=w_{r f} R_{f}+E\left[\sum_{i=1}^{N} w_{p i} R_{i}\right] \\
\sigma^{2}\left(R_{p}\right)=E\left\{\left[R_{p}-E\left(R_{p)}\right]^{2}\right\}\right. \\
s^{3}\left(R_{p}\right)=E\left\{\left[R_{p}-E\left(R_{p)}\right]^{3}\right\}^{2}\right.
\end{gathered}
$$

In the further course, the present study follows Diacogiannis (1994) and uses vectorial notation given by:

$$
\begin{gathered}
E\left(R_{p}\right)=w_{r f} R_{f}+\boldsymbol{w}_{\boldsymbol{p}^{\prime}} \boldsymbol{E} \\
\sigma^{2}\left(R_{p}\right)=\boldsymbol{w}_{\boldsymbol{p}^{\prime}} \boldsymbol{\Omega}_{\boldsymbol{p}} \\
s^{3}\left(R_{p}\right)=\boldsymbol{w}_{\boldsymbol{p}^{\prime}} \boldsymbol{\Sigma}_{\boldsymbol{p}}
\end{gathered}
$$

with

$$
\boldsymbol{w}_{\boldsymbol{p}^{\prime}} \mathbf{1}=\left(1-w_{r f}\right)
$$

$\boldsymbol{w}_{\boldsymbol{p}^{\prime}}$ is the $(1 \times N)$ transposed vector of risky asset weights and $\boldsymbol{w}_{\boldsymbol{p}}$ is the $(N \times 1)$ vector of the $N$ risky assets in the investor's portfolio. $\boldsymbol{E}$ is a $(N x 1)$ vector of the expected returns from the risky assets and $\boldsymbol{\Omega}$ is the covariance matrix of the returns from the $N$ risky assets. $\boldsymbol{\Sigma}_{\boldsymbol{p}}$ represents a $(N x 1)$ vector of coskewness between the security returns and the portfolio returns. $\mathbf{1}$ is a $(N x 1)$ unitary vector.

An investor $k^{\prime} s$ portfolio problem can be represented as:

${ }^{2}$ This measure of skewness represents the centred third moment, while, in general, skewness corresponds to the standardized third centred moment. 


$$
\max _{w_{p}}\left\{E\left[U_{k}\left(R_{p}\right)\right]\right\}=\operatorname{Max}\left\{V_{k}\left[E\left(R_{p}\right), \sigma^{2}\left(R_{p}\right), s^{3}\left(R_{p}\right)\right]\right\}
$$

Subject to

$$
\boldsymbol{w}_{\boldsymbol{p}^{\prime}} \mathbf{1}=\left(1-w_{r f}\right)
$$

The first-order conditions for a maximum are given by:

$$
\frac{\partial V_{k}(.)}{\partial \boldsymbol{w}_{\boldsymbol{p}}}=V_{k}^{(1)} \frac{\partial E\left(R_{p}\right)}{\partial \boldsymbol{w}_{\boldsymbol{p}}}+V_{k}^{(2)} \frac{\partial \sigma^{2}\left(R_{p}\right)}{\partial \boldsymbol{w}_{\boldsymbol{p}}}+V_{k}^{(3)} \frac{\partial s^{3}\left(R_{p}\right)}{\partial \boldsymbol{w}_{\boldsymbol{p}}}=0
$$

and can be rewritten as

$$
\frac{\partial V_{k}(\cdot)}{\partial \boldsymbol{w}_{\boldsymbol{p}}}=V_{k}^{(1)}\left(\boldsymbol{E}-\mathbf{1} \boldsymbol{R}_{\boldsymbol{f}}\right)+2 V_{k}^{(2)} \boldsymbol{\Omega} \boldsymbol{w}_{\boldsymbol{p}}+3 V_{k}^{(3)} \boldsymbol{\Sigma}_{\boldsymbol{p}}=0^{3}
$$

Invoking a two-fund monetary separation theorem, summing demand across all investors and assuming that the optimum risky portfolio weights correspond to those of the market portfolio, dividing by the partial derivative of the utility function with respect to the portfolio return and rearranging the expression, yields the following equilibrium relationship:

$$
\boldsymbol{E}-\boldsymbol{1} \boldsymbol{R}_{\boldsymbol{f}}=\left[-\frac{2 V^{(2)}}{V^{(1)}}\right] \boldsymbol{\Omega} \boldsymbol{w}_{\boldsymbol{m}}+\left[-\frac{3 V^{(3)}}{V^{(1)}}\right] \boldsymbol{\Sigma}_{\boldsymbol{m}}
$$

With

$$
\mathbf{1}^{\prime} \boldsymbol{w}_{\boldsymbol{m}}=1
$$

$\boldsymbol{w}_{\boldsymbol{m}}$ is the (Nx1) vector of the asset weights of the market portfolio. $\boldsymbol{\Omega}_{\boldsymbol{m}}$ and $\boldsymbol{\Sigma}_{\boldsymbol{m}}$ represent the (Nx1) vectors of covariance and coskewness between the returns on the risky assets and those on the market portfolio. Modifying this expression gives:

$$
E-\mathbf{1} R_{f}=\left[-\frac{2 V^{(2)}}{V^{(1)}}\right] \sigma^{2}\left(R_{m}\right) \frac{\Omega w_{m}}{\sigma^{2}\left(R_{m}\right)}+\left[-\frac{3 V^{(3)}}{V^{(1)}}\right] s^{3}\left(R_{m}\right) \frac{\boldsymbol{\Sigma}_{m}}{s^{3}\left(R_{m}\right)}
$$

This results in the following representation for a CAPM, including the third moment of the return distribution:

$$
\boldsymbol{E}-\mathbf{1} R_{f}=b_{1} \boldsymbol{\beta}+b_{2} \boldsymbol{\gamma}
$$

With:

$$
\boldsymbol{\beta}=\frac{\boldsymbol{\Omega} \boldsymbol{w}_{\boldsymbol{m}}}{\sigma^{2}\left(R_{m}\right)}
$$




$$
\boldsymbol{\gamma}=\frac{\Sigma_{m}}{s^{3}\left(R_{m}\right)}
$$

And:

$$
\begin{aligned}
& b_{1}=\omega_{1} \sigma^{2}\left(R_{m}\right) \\
& b_{2}=\omega_{2} s^{3}\left(R_{m}\right)
\end{aligned}
$$

with $\omega_{1}=-\frac{2 V^{(2)}}{V^{(1)}}$ and $\omega_{2}=-\frac{3 V^{(3)}}{V^{(1)}}$ which are measures of a representative investor's aversion to variance and his preference for (positive) skewness. $\boldsymbol{\beta}$ is the $(N x 1)$ vector of relative covariances (covariances adjusted by the variance of the market portfolio) and $\boldsymbol{\gamma}$ describes the relative coskewness vector.

As this relationship has to apply not only to the market portfolio but to all securities $i, i=$ $[1, \ldots . N]$, the relationship can also be written as:

$$
E\left(R_{i}\right)-R_{f}=b_{1} \beta_{i}+b_{2} \gamma_{i}
$$

With

$$
\begin{aligned}
& \beta_{i}=\frac{\operatorname{Cov}\left(R_{i}, R_{m}\right)}{\sigma^{2}\left(R_{m}\right)} \\
& \gamma_{i}=\frac{\operatorname{Cov}\left(R_{i}, R_{m}\right)}{s^{3}\left(R_{m}\right)}
\end{aligned}
$$

Therefore, in equilibrium, the excess return on any asset $i$, with $i=[1, \ldots, N]$, is linearily dependent on the parameters $\beta_{i}$ and $\gamma_{i}$. These parameters indicate the extent to which asset $i$ contributes to the variance and skewness of the market portfolio return. The coefficients $b_{1}$ and $b_{2}$ can be interpreted as premiums for non-diversifiable or systematic market risk. Since $\omega_{1}$ and $\sigma^{2}\left(R_{m}\right)$ is positive, $\beta_{i}$ evokes a positive risk premium. Since $\omega_{2}$ is negative, $\gamma_{i}$ should exhibit the opposite sign to that of market skewness $s^{3}\left(R_{m}\right)$. The economic intuition is straightforward. If the market is positively skewed, an investor is willing to accept a lower return for an asset which exhibits positive coskewness with the market. If the asset has negative coskewness with the market, an investor requires a higher return to induce him to allocate funds to this asset. If the market is negatively skewed, an investor is willing the pay a premium for an asset exhibiting negative coskewness, but requires a higher return for an asset which features positive coskewness. Therefore, the market price of coskewness is expected to have the opposite sign to that of market skewness. 


\subsection{Data \& Descriptive Statistics}

The sample consists of all traded and defunct European real estate and general equities from June 1988 to June 2009 and is based on Schulte et al. (2011). All data is downloaded from Thomson Reuters Datastream. The study examines 16 European countries, namely Austria, Belgium, Czech Republic, Denmark, Finland, France, Germany, Greece, Ireland, Italy, The Netherlands, Norway, Portugal, Spain, Sweden and the United Kingdom. The sample of general equities is collected from Thomson Reuters' research indices. These do not have any size restriction and are therefore more appropriate for reflecting the market portfolio and analyzing a potential small-size effect ${ }^{4}$. Due to the documented issues with individual equity return data from Thomson Reuters Datastream, the correction procedures proposed by Ince and Porter (2006) are performed on the initial sample of 37,572 equities. To deal with potential coverage issues, any firm incorporated outside the respective country is removed from the sample. Moreover, all non-common equities are excluded. A screening process excludes all remaining shares that are wrongly classified as common equity, such as closed-end funds, shares of beneficial interest, ADRs, warrants etc. This reduces the sample to 15,501 companies, a reduction of almost $60 \%$. The 369 constituents of the GPR General Quoted Europe Index are used to proxy the European real estate equity market ${ }^{5}$. Excluding companies that are situated outside the analyzed countries, as well as those that are not covered by Thomson Reuters, results in a sample of 335 companies. Total return indices, share prices as well as the market and book value of equity are extracted for each stock. All variables are denominated in Euros ${ }^{6}$. Total returns are calculated as monthly discrete returns. Due to the methodology of Thomson Reuters Datastream regarding total return data, it is not possible to distinguish between zero monthly returns, trading suspensions or missing returns. Zero monthly returns are therefore dropped from the sample.

Following Fama and French $(1993,1996)$, size and BE/ME are used to sort all stocks at the end of June of each year $\mathrm{t}^{7}$. Size is calculated as a firm's market value of equity at the end of June year $\mathrm{t}$. $\mathrm{BE} / \mathrm{ME}$ is calculated by dividing a firm's book value of equity at the end of year t- 1 by its market value of equity at the end of June year t. For a stock to be included in the analysis, it needs to have data available on size and a non-negative BE/ME. Following Ince and Porter (2006), stocks with

\footnotetext{
${ }^{4}$ As Fama and French (1998) and Liew and Vassalou (2000) emphasize, using a database of large stocks does not allow for an identification or test for a small-size effect. Therefore, any sample without a size restriction should yield more robust results. Details on the research lists can be found in Table 1 of the online appendix or can be requested from the authors.

${ }^{5}$ The authors wish to thank Global Property Research for providing the index constituents.

${ }^{6}$ Using total returns denominated in a single currency follows similar studies, such as Fama and French (1998) and Bauer et al. (2010). However, using total returns in local currency rather than Euro is performed as a robustness check.

${ }^{7}$ The study does not consider the Carhart (1997) momentum factor. This is due to the inability to perform a three-sequential sorting procedure as a cause of the limited amount of real estate equities. By including the momentum factor, the two-sequential procedure would not be able to disentangle the effects and might result in spurious results.
} 
a share price below $1.00 €$ are excluded from the analysis. The screening process results in a final sample of 9,662 general and 275 real estate equities.

The study employs the two-sequence sorting procedure of Liew and Vassalou (2000) ${ }^{8}$. All general equities are ranked by size at the end of June of each year t. The median is used to split the sample into small (S1) and big stocks (S2). Subsequently, the stocks in each portfolio are subdivided by their $\mathrm{BE} / \mathrm{ME}$ ratio. $30 \%$ of the stocks with the highest and lowest $\mathrm{BE} / \mathrm{ME}$ ratios are allocated to the high (B1) and low (B3) portfolio respectively, while the remaining $40 \%$ are sorted into the medium (B2) portfolio. The portfolio composition is maintained for a holding period of twelve months. Monthly total returns are calculated for each portfolio, as the equally-weighted average return of all stocks in the respective portfolio'. SMB (Small minus Big) is the return on a portfolio mimicking the risk factor related to size, and is calculated as the average of monthly total returns on the three small-stock portfolios (S1/B1, S1/B2, S1/B3), minus the average of monthly total returns on the three big-stock portfolios (S2/B1, S2/B2, S2/B3). Similarly, HML (High minus Low) is the return on a portfolio mimicking the risk factor related to book-to-market equity, and is calculated as the average of monthly total returns on the two high-BE/ME portfolios (S1/B1, $\mathrm{S} 2 / \mathrm{B} 1)$, minus the average of monthly total returns on the two low-BE/ME portfolios (S1/B3, $\mathrm{S} 2 / \mathrm{B} 3)$. The market factor is calculated as the equally-weighted average excess return of all stocks in the final sample. The risk-free rate is the equally-weighted average of all 16 one-month interbank rates. The test assets are 16 real estate portfolios, which are formed in a similar way using the size and BE/ME quartiles as breakpoints. The sorting procedure results in an annual average of 664 general equities and 6 real estate equities in each portfolio ${ }^{10}$.

While the resulting average market capitalization of real estate stock amounts to roughly $€ 666 \mathrm{~m}$, general equities are significantly larger, with an average market capitalization of $€ 1,232 \mathrm{~m}$. Similarly, the average BE/ME of general equities (1.67) is significantly higher than that of real estate stocks, which have an average BE/ME of roughly 1.34. Tables 1 and 2 summarize the resulting return characteristics on both the 16 real estate and six general equity portfolios from July 1988 to June 2009 (252 months). The returns on the 16 real estate and six general equity portfolios largely follow the expected pattern, in that small size and high BE/ME stocks outperform

\footnotetext{
${ }^{8}$ The approach of combining data from all countries follows Fama and French (2006), Bauer et al. (2010) as well as Schulte et al. (2011) and is necessary, due to the limited number of listed real estate companies per country. This approach requires a reasonable degree of (real estate) capital market integration and/or that industry effects dominate country effects. Previous studies yield mixed results. While Fratzscher (2002), Hardouvelis et al. (2006), Cappiello et al. (2008), Bekaert et al. (2009) as well as Morelli (2010) provide evidence of capital market integration from the mid80s/-90s onwards, other researchers such as Griffin (2002) and Moerman (2005) emphasize that domestic asset pricing models perform better than their global/European counterparts. However, Baca et al. (2000) as well as Moerman (2005) stress the fact that industry factors have not only increased in importance, but are more important than country effects, which justifies the approach used in the present paper.

${ }^{9}$ Using value-weighted instead of equally-weighted returns might cause the size effect to decrease or diminish, as the allegedly lower returns of larger stocks are accentuated. However, using value-weighted instead of equally-weighted returns is performed as a robustness check.

${ }^{10}$ Details on the number of companies in each portfolio and year can be found in Table 2 and 3 of the online appendix or can be requested from the authors.
} 
large size and low BE/ME stocks respectively. However, there is some unexpected return behaviour in the larger size and lower BE/ME portfolios. The returns suggest that within the real estate and general equity portfolios, a monthly value effect of $0.64 \%$ (t-stat: 2.75 ) and $1.11 \%$ (tstat: 6.88) is present respectively. A size effect does not seem to be statistically significant in neither the real estate $(0.13 \%$, t-stat: 0.58$)$ nor general equity market $(0.11 \% \text {, t-stat: } 0.99)^{11}$.

- Insert Table $1 \& 2$ about here -

As indicated, most real estate portfolio returns follow a non-normal distribution, which is highlighted by significant values of skewness and kurtosis. Skewness and kurtosis seem to be much more prevalent in the second subsample and during the financial crisis, as evinced by more significant coefficients. The returns of the general equity portfolios show a similar pattern in that skewness is more present in the second subsample and during the financial crisis, whereas kurtosis seems to dominate during the first subsample.

\subsection{Methodology and Research Design}

A methodology similar to that of Fama and French $(1993,1996,1997)$ is employed to conduct the asset pricing tests. The empirical analysis runs from July $1988(\mathrm{~m}=1)$ to June $2009(\mathrm{~m}=252)$ and proceeds in two stages. In the first, time-series ordinary least squares (OLS) regressions of excess portfolio returns on the excess market return, SMB and HML are performed. The resulting coefficients indicate whether European real estate stocks load on the systematic risk factors. Two additional time-series regressions include the orthogonalised squared excess market return and the orthogonalised squared market return deviation from its mean respectively. Their coefficients are subsequently used as proxies for unconditional systematic coskewness. In the second stage, the portfolio factor loadings from the first stage are assigned to individual equities, depending on which portfolio the stock was assigned to. Monthly Fama-MacBeth (1973) cross-section regressions of individual real estate equity returns on the assigned loadings and the measures of unconditional systematic coskewness are performed to determine factor risk premiums ${ }^{12}$. In order

\footnotetext{
${ }^{11}$ Further details on the portfolio returns, sizes and BE/ME ratios can be found in Table 4 and 5 of the online appendix or can be requested from the authors.

${ }^{12}$ The approach of Fama and French $(1993,1996)$ uses 25 portfolios as test assets. This would result in a very limited number of real estate equities in each portfolio. The approach of assigning 16 group loadings to individual equities is similar to studies by Fama and MacBeth (1973), Fama and French (1992) as well as Conover et al. (2000) and is a trade-off between a sufficient spread in the loadings and their stability.
} 
to estimate whether a risk factor is priced, time-series averages of monthly cross-section coefficients are computed and t-tests with Fama-MacBeth standard errors adjusted for serial correlation are conducted ${ }^{13}$. The cross-section regressions are also conducted conditionally on whether the excess market return is positive or negative as in Pettengill et al. $(1995,2002)$.

\subsubsection{Measures of Unconditional Coskewness}

The study uses four different measures of unconditional systematic coskewness. The first two are based on Harvey (2000) as well as Harvey and Siddique (2000) and are defined as

$$
\begin{gathered}
\hat{\zeta}_{p, m}^{1}=\frac{E\left[\varepsilon_{p, m} \varepsilon_{M, m}^{2}\right]}{\sqrt{E\left[\varepsilon_{p, m}^{2}\right] E\left[\varepsilon_{M, m}^{2}\right]}} \\
\hat{\varsigma}_{p, m}^{2}=\frac{E\left[\varepsilon_{p, m} \varepsilon_{M, m}^{2}\right]}{\left[\sigma\left(\varepsilon_{M, m}\right)\right]^{3}}
\end{gathered}
$$

where $\varepsilon_{p, m}$ is the residual from regressing the excess return of portfolio $\mathrm{p}$ on a constant and the contemporaneous market excess return, $r_{p, m}-r f_{m}=\alpha_{p}+\hat{b}_{p}\left(r m_{m}-r f_{m}\right)+\varepsilon_{p, m} \cdot \varepsilon_{M, m}$ is the difference of the market return from its mean value, $\varepsilon_{M, m}=r m_{m}-r m$. Both measures are direct, standardized measures of unconditional coskewness and measure the contribution of each real estate portfolio to the skewness of the market portfolio. One benefit of using unconditional coskewness is that the coefficient can be interpreted, irrespective of the skewness of the market portfolio. Therefore, a negative coefficient implies that the portfolio is adding negative skewness to the market portfolio and, accordingly, should have a higher expected return.

The second two measures of unconditional coskewness are derived by regressing the excess return of portfolio $\mathrm{p}$ on a constant, the excess market return, SMB and HML as well as either the orthogonalised squared excess market return or the orthogonalised squared market return deviation. The coefficients of the two latter represent the proxies for systematic coskewness. In order to obtain unconditional measures that are comparable to $\hat{\zeta}_{p, m}^{1}$ and $\hat{\varsigma}_{p, m}^{2}$, both the squared excess market return and the squared market return deviation are orthogonalised by regressing

\footnotetext{
${ }^{13}$ Shanken (1992) points out that the Fama-MacBeth (1973) procedure overstates the precision of risk premiums by ignoring that the factor loadings employed as independent variables are estimated in the rolling first stage time-series regressions. Shanken (1992) proposes a correction procedure to circumvent this error-in-variables (EIV) problem. However, the procedure is not applicable when assigning group loadings to individual equity returns. Nevertheless, Cochrane (2005) points out that the EIV problem is only significant in low frequency data while being negligible when monthly data is used.
} 
either on a constant and the excess market return and using the residuals in the subsequent regression (Harvey and Siddique, 2000). Similarly, a negative coefficient implies that the portfolio is adding negative skewness to the market portfolio and, accordingly, should have a higher expected return.

\subsubsection{Time-Series Regressions}

For each portfolio and for the period from July $1988(\mathrm{~m}=1)$ to June $2009(\mathrm{~m}=252)$, the following set of time-series regressions are run

$$
\begin{gathered}
r_{p, m}-r f_{m}=\alpha_{p, m}+\hat{b}_{p, m}\left(r m_{m}-r f_{m}\right)+\hat{s}_{p, m} S M B_{m}+\hat{h}_{p, m} H M L_{m}+\varepsilon_{p, m} \\
r_{p, m}-r f_{m}=\alpha_{p, m}+\hat{b}_{p, m}\left(r m_{m}-r f_{m}\right)+\hat{s}_{p, m} S M B_{m}+\hat{h}_{p, m} H M L_{m}+\hat{\gamma}_{p, m}^{1}\left(r m_{m}-r f_{m}\right)_{\perp}^{2}+\varepsilon_{p, m}(12) \\
r_{p, m}-r f_{m}=\alpha_{p, m}+\hat{b}_{p, m}\left(r m_{m}-r f_{m}\right)+\hat{s}_{p, m} S M B_{m}+\hat{h}_{p, m} H M L_{m}+\hat{\gamma}_{p, m}^{2}\left(r m_{m}-r m\right)_{\perp}^{2}+\varepsilon_{p, m}(
\end{gathered}
$$

$\mathrm{m}=1,2, \ldots, 252$

where $r_{p, m}-r f_{m}$ is the excess return on portfolio $\mathrm{p}$ and $r m_{m}-r f_{m}$ is the excess return on the market portfolio in month m. $S M B_{m}$ and $H M L_{m}$ are the two additional risk factors for capturing the size and book-to-market equity effect. $\left(r m_{m}-r f_{m}\right)_{\perp}^{2}$ and $\left(r m_{m}-\overline{r m}\right)_{\perp}^{2}$ are the orthogonalised squared excess market return and the squared market return deviation. $\hat{b}_{p, m}, \hat{s}_{p, m}$ and $\hat{h}_{p, m}$ are the estimated factor loadings of portfolio p. $\hat{\gamma}_{p, m}^{1}$ and $\hat{\gamma}_{p, m}^{2}$ are the two proxies for unconditional systematic coskewness. $\alpha_{p, m}$ represents the pricing error of portfolio $\mathrm{p}$.

Following previous studies such as Fama and French (1997) and Hung et al. (2004), monthly rolling time-series regressions are performed to account for time-varying factor loadings. At the end of each month $\mathrm{m}$, the factor loadings are estimated using data for the last five years. This results in losing the first five years of data, as the first set of factor loadings is obtained in June $1993^{14}$. Subsequently, the estimation period is rolled one month forward and the regressions are

\footnotetext{
${ }^{14}$ The five-year window for estimating the factor loadings is in line with previous studies, such as Chen et al. (1986), Fama and French (1997) and Hung et al. (2004).
} 
repeated. The same rolling window is applied when calculating $\left(r m_{m}-r f_{m}\right)_{\perp}^{2}$ and $\left(r m_{m}-\overline{r m}\right)_{\perp}^{2}$ as well as $\hat{\zeta}_{p, m}^{1}$ and $\hat{\zeta}_{p, m}^{2}$.

\subsubsection{Cross-Section Regressions}

The cross-section regressions build upon the coefficient estimates from the rolling time-series regressions. Each month, the excess returns of individual real estate equities are matched to their respective factor loadings $\hat{b}_{p, m}, \hat{s}_{p, m}, \hat{h}_{p, m}, \hat{\gamma}_{p, m}^{1}, \hat{\gamma}_{p, m}^{2}$ as well as $\hat{\zeta}_{p, m}^{1}$ and $\hat{\zeta}_{p, m}^{2}$, depending on the portfolio to which the stock was allocated. Subsequently, monthly unconditional OLS FamaMacBeth (1973) cross-section regressions of individual equity returns on the assigned factor loadings are conducted ${ }^{15}$. Due to the five-year rolling window, the regressions run from July 1993 $(\mathrm{m}=61)$ to June $2009(\mathrm{~m}=252)$ and can be expressed as

$$
\begin{gathered}
r_{i, m+1}-r f_{m+1}=\lambda_{b, m+1} \hat{b}_{p, m}+\lambda_{s, m+1} \hat{s}_{p, m}+\lambda_{h, m+1} \hat{h}_{p, m}+\varepsilon_{i, m+1} \\
r_{i, m+1}-r f_{m+1}=\lambda_{b, m+1} \hat{b}_{p, m}+\lambda_{s, m+1} \hat{s}_{p, m}+\lambda_{h, m+1} \hat{h}_{p, m}+\lambda_{C S K, m+1} C S K_{p, m}+\varepsilon_{i, m+1}
\end{gathered}
$$

$\mathrm{m}=60,61, \ldots, 251$

where $r_{i, m+1}-r f_{m+1}$ is the excess return on stock $\mathrm{i}$ in month $\mathrm{m}+1 . \hat{b}_{p, m}, \hat{s}_{p, m}$, and $\hat{h}_{p, m}$ are the monthly loadings on the Fama-French factors from the first-stage regressions, while $C_{\text {S }} K_{p}$ represents the respective measure of unconditional systematic coskewness, namely either $\wedge_{p, m}^{\wedge}, \stackrel{\wedge_{p, m}}{\wedge_{p, m}}$ or $\wedge_{p, m}^{2}$ . $\lambda_{b, m+1}, \lambda_{s, m+1}$ and $\lambda_{h, m+1}$ are the estimated factor risk premiums regarding the sensitivities to the Fama-French factors, while $\lambda_{C S K, m+1}$ represents the respective factor risk premium related to coskewness, namely either $\lambda_{\varsigma^{1}, m+1}, \lambda_{\varsigma^{2}, m+1}, \lambda_{\gamma^{1}, m+1}$ or $\lambda_{\gamma^{2}, m+1}$. The error term $\varepsilon_{i, m+1}$ is the pricing error of the cross-section regression ${ }^{16}$. As $\hat{b}_{p, m}, \hat{s}_{p, m}$, and $\hat{h}_{p, m}$ are the sensitivities to systematic risk factors, higher loadings on the excess market return, SMB and HML should imply higher expected returns. Similarly, as a negative coskewness measure implies that the portfolio is adding negative skewness to the market portfolio, portfolios with a lower coefficient should have higher

\footnotetext{
${ }^{15}$ Cross-section GLS regressions should improve efficiency, i.e., yield more precise results than OLS. However, the precision gained often results in a sacrifice of robustness. Therefore, this study follows Cochrane (2005), who suggests choosing the robustness of OLS over the asymptotic statistical advantages of GLS.

${ }^{16}$ Following Cochrane (2005), the intercept is imposed as zero and therefore the residuals of the regressions represent the pricing error.
} 
expected returns.

Pettengill et al. $(1995,2002)$ suggest that the inability of many asset pricing studies to establish a relationship between cross-sectional returns and risk factors (predominantly beta) results from the aggregation of positive and negative excess market return periods, when using realised returns to proxy for expected returns. They argue that when the excess market return is negative, an inverse relationship between cross-sectional returns and risk factors should emerge, which is supported by Pettengill et al. (1995, 2002), Fletcher (1997, 2000) and Schulte et al. (2011). To account for timevarying asset behaviour, the Fama-MacBeth regressions are also conducted conditionally following Pettengill et al. (1995, 2002). If the excess market return in month $m+1$ is positive, a month is classified as an up-market state, otherwise as a down-market state. Using this classification, 114 bull months and 78 bear months are identified. The regressions are performed on both market segments separately, so as to examine the risk premiums in each market state. Based on the findings regarding the importance of a real estate factor in the pricing of real estate equities (Clayton and MacKinnon, 2003; Chiang et al., 2006, Lee et al., 2008, Schulte et al., 2011), the regressions are also conditioned on whether the real estate equity market is in an up- or a downmarket state. Using the same condition as above, 110 real estate up- and 82 real estate downmarket states are identified for the subsequent analysis.

The monthly conditional OLS Fama-MacBeth (1973) cross-section regressions are given as

$$
\begin{gathered}
r_{i, m+1}-r f_{m+1}=\delta_{m+1} \lambda_{b, m+1}^{+} \hat{b}_{p, m}+\left(1-\delta_{m+1}\right) \lambda_{b, m+1}^{-} \hat{b}_{p, m}+\delta_{m+1} \lambda_{s, m+1}^{+} \hat{s}_{p, m}+\left(1-\delta_{m+1}\right) \lambda_{s, m+1}^{-} \hat{s}_{p, m} \\
+\delta_{m+1} \lambda_{h, m+1}^{+} \hat{h}_{p, m}+\left(1-\delta_{m+1}\right) \lambda_{h, m+1}^{-} \hat{h}_{p, m}+\delta_{m+1} \varepsilon_{i, m+1}^{+}+\left(1-\delta_{m+1}\right) \varepsilon_{i, m+1}^{-}
\end{gathered}
$$

$$
\begin{aligned}
& r_{i, m+1}-r f_{m+1}=\delta_{m+1} \lambda_{b, m+1}^{+} \hat{b}_{p, m}+\left(1-\delta_{m+1}\right) \lambda_{b, m+1}^{-} \hat{b}_{p, m}+\delta_{m+1} \lambda_{s, m+1}^{+} \hat{s}_{p, m}+\left(1-\delta_{m+1}\right) \lambda_{s, m+1}^{-} \hat{s}_{p, m}+\delta_{m+1} \lambda_{h, m+1}^{+} \hat{h}_{p, m} \\
& \quad+\left(1-\delta_{m+1}\right) \lambda_{h, m+1}^{-} \hat{h}_{p, m}+\delta_{m+1} \lambda_{C S K, m+1}^{+} C S K_{p, m}+\left(1-\delta_{m+1}\right) \lambda_{C S K, m+1}^{-} \operatorname{CSK} K_{p, m}+\delta_{m+1} \varepsilon_{i, m+1}^{+}+\left(1-\delta_{m+1}\right) \varepsilon_{i, m+1}^{-} \\
& \mathrm{m}=60,61, \ldots, 251
\end{aligned}
$$

where $\delta_{m+1}$ is a dummy variable equal to 1 , when the excess market return in month $\mathrm{m}+1$ is positive $\left(r m_{m+1}-r f_{m+1}\right)>0$ and 0 if the excess market return is negative $\left(r m_{m+1}-r f_{m+1}\right)<0$. Equations (14a) 
and (14b) are examined for each month, by estimating the factor risk premiums $\gamma_{b, m+1}^{+}, \gamma_{s, m+1}^{+}, \gamma_{h, m+1}^{+}$ and the respective $\lambda_{C S K, m+1}^{+}$for up- or $\gamma_{b, m+1}^{-}, \gamma_{s, m+1}^{-}, \gamma_{h, m+1}^{-}$and the respective $\lambda_{C S K, m+1}^{-}$for downmarkets with the corresponding pricing errors $\varepsilon_{i, m+1}^{+}$and $\varepsilon_{i, m+1}^{-}$. Higher loadings on the excess market return, SMB and HML should imply higher returns in up-markets and lower returns in down-markets. Similarly, portfolios which add negative skewness to the market portfolio should receive higher returns in up-markets and lower returns in down-markets.

\subsection{Time-Series Regression Results}

Panel I to III of Table 3 present the time-series regression results of Equation (12a), (12b) and (12c). For ease of understanding, the results of the time-series regressions are based on full sample loadings instead of the proposed time-varying loadings as discussed in Section 2.5.2 ${ }^{17}$.

- Insert Table 3 about here -

Panel I of Table 3 shows the time-series regression results of Equation (12a). Similar to Schulte et al. (2011), the excess market return is a strong driver of European real estate equity returns, as all portfolios show significantly positive coefficients. While six portfolios load negatively on SMB and accordingly behave like big-capitalization stocks, one portfolio loads positively on SMB, the other remaining uninfluenced. All but one portfolio load positively on HML, indicating the valuestock characteristics of European real estate equities. Eight portfolios yield significantly negative pricing errors, which are mainly noticeable in the large size real estate portfolios. The average Rsquared is as high as $45.3 \%$ across all portfolios. The number of pricing errors declines significantly when the financial crisis is excluded from the sample, while the loading on the excess market return, SMB and HML do not seem to be affected. However, the results for the first subsample reveal the subordinate role of SMB and HML prior to the introduction of the Euro. While all portfolios continue to load positively on the excess market return, only two portfolios load on SMB and three on HML. Similarly, the average R-squared is significantly lower (40\%) and seven portfolios reveal significant pricing errors. In contrast, the asset pricing model performs much better in the second subsample. This is indicated by only three portfolios with pricing errors,

${ }^{17}$ The results concerning the different subsamples can be found in the online appendix or can be requested from the authors. 
seven significant loadings on SMB and 15 significant loadings on HML. Moreover, the average R-squared of $52.5 \%$ is significantly higher than in the first subsample.

When the orthogonalised squared excess market return and the squared market return deviation are included as in Equation (12b) and (12c), the goodness of the model does not increase significantly, as evinced by marginally higher R-squared. Moreover, only a limited number of portfolios yield significant loadings on the two additional factors. However, as Panel II and III of Table 3 reveal, there are several noticeable differences. Firstly, the inclusion of the squared excess market return and the squared market return deviation reduces the number of pricing errors in the first and second subsample. Secondly, both factors seem to absorb some of the explanatory power of SMB when the financial crisis is excluded from the sample, as some coefficients decrease in significance and even become insignificant in some cases. However, as the results in the first subsample indicate, both factors seem to increase the significance of SMB prior to the introduction of the Euro. Apparently, both factors help in capturing the tail distributions of some portfolio returns, allowing SMB to explain the remaining variation. This seems to be the case mainly with respect to the small and big-size portfolios. This also seems to apply to HML, although to a limited extent.

\subsection{Cross-Section Regression Results}

Table 4 presents time-series averages of slopes from monthly Fama-MacBeth (FM) regressions of the cross-section of returns on the loadings of the systematic risk factors. The average slopes provide standard FM tests for determining which explanatory variables, on average, have non-zero expected premiums from July 1993 to June 2009.

- Insert Table 4 about here -

The results from unconditional cross-section regressions on the loadings on the systematic risk factors of the Fama-French three-factor model (Panel I) show a weak positive relationship between beta and cross-sectional returns between July 1993 and June 2009. However, controlling for the effects of the financial crisis by excluding the period from June 2007 onwards, reveals a strong and positive link between beta and returns. This higher explanatory power is likely to result from the fact that high beta stocks yield very low returns during the financial crisis, weakening the 
impact of beta in the full-sample model. Excluding this period controls for the effect and indicates that a conditional pricing model might be able to capture cross-sectional return variations more accurately. In contrast to the results from regressing returns on beta, the relationship between cross-sectional returns and the risk premiums on SMB and HML is too flat to identify any significant unconditional pricing effect across all analyzed samples.

However, the amount of systematic risk impacts on returns in a conditional manner. While high beta stocks outperform in up markets, they yield lower returns in down markets. These results are persistent across all subsamples and are not dependent on the conditioning variable. They are in accordance with the findings of Pettengill $(1995,2002)$ and the perception of beta as a risk factor. Real estate equities which load high on SMB, however, yield higher returns during market downturns, but perform worse when the (real estate) market performs above the risk free rate. This is contrast with the risk-based argument of size, but in accordance with earlier studies like Hung (2007), who finds similar results in European equity markets. Furthermore, in line with the perception of HML as a risk factor, there is some indication that stocks with a higher loading on HML outperform in up but underperform in down markets. This effect is evident in the first subsample.

The inclusion of coskewness as an explanatory variable in cross-section regressions reveals some interesting results (Panel II to V). Coskewness does not add much explanatory power to unconditional and conditional cross-section regressions, as the average $\mathrm{R}^{2}$ does not increase significantly. This holds independently of the particular measure of coskewness. Therefore, coskewness has either no incremental or only marginal explanatory power over the loadings on the Fama-French factors. Similar conclusions are drawn by Lin and Wang (2003) as well as Misirli and Alper (2009) for the Taiwanese and the Turkish stock market, respectively. Moreover, the four measures of coskewness employed in unconditional cross-sectional regressions yield mixed results with regard to their levels of significance in different samples. Nonetheless, the loadings on coskewness carry the expected negative sign in 14 of 16 cases, indicating that equities which contribute negatively to the skewness of the market yield, on average, higher returns than assets with lower coskewness. However, only two loadings exhibit statistical significance at the $10 \%$ level. These significances occur when the analysis is conducted throughout the entire sample period and in the second subsample. Albeit the results are - in terms of significance - not consistent across all measures of coskewness, the third comoment is, beside beta, the only factor to exhibit significant explanatory power in unconditional regressions. This is an indication that coskewness plays a vital role in real estate asset pricing, as it captures some effects which are not accounted for by the remaining factors. As mentioned above, the role of coskewness is evident mainly in the 
second part of the sample. However, coskewness evokes no significant risk premium in unconditional ex-crisis-cross-sectional regressions and in the first subsample. This outcome is likely to stem from the fact that coskewness is designed to capture extreme deviations which occur jointly with those of the market return - a return behavior which occurred during the financial crisis. This is also revealed by the higher skewness of real estate portfolio returns in the full and second sub-sample, as shown in Section 2.4.

The results from conditional full-sample cross-section regressions yield further findings which underpin the explanatory power of the third comoment. While real estate equities with lower coskewness tend to outperform in up-markets, they underperform in most down-market states. This pricing pattern is consistent with the risk-based argument of coskewness, as riskier equities, i.e. those which contribute negatively to market skewness, should have higher average returns in up-markets, but also perform worse in down-markets. Equities which contribute positively to market skewness are supposed to yield higher returns in down-markets, but to underperform in upmarkets. This result holds independent of whether the regressions are conditioned on the general or the real estate equity market. The conditional explanatory power of coskewness is also evident throughout various subsamples, in particular when conditioned on whether the real estate market performs above or below the risk-free rate of return and in the second subsample - which is again likely to be an effect of extreme returns associated with the financial crisis.

In terms of significance, the results on the four measures of coskewness are, again, not conclusive. Depending on the specific measure, the number of significances is different and they occur in different subsamples. However, the results might be influenced by country, weighting or currency effects, which will be addressed in the robustness section.

One result that is evident throughout the cross-section regressions is that the inclusion of coskewness affects the significance of the loadings on SMB. Although the down market outperformance (underperformance) of real estate equities which load higher (lower) on SMB is still evident when coskewness is included, the t-statistics of the average SMB loading is consistently reduced. This implies a relation between size and coskewness, which is also found by Lin and Wang (2003) as well as Misirli and Alper (2009). To investigate this relationship more in detail, 16 size-sorted portfolios are constructed and tested on whether average size is related to unconditional coskewness. The unreported results show that smaller size portfolios have a higher average coskewness than large portfolios and that average size is negatively correlated to the average coskewness measure HS1 (-0.35) and HS2 (-0.41), respectively. This appears predominantly in down-states of the real estate (HS1:-0.41, HS2: -0.45) and general equity market 
(HS1: -0.35, HS2: -0.43) and indicates that an asset pricing model which does not account for coskewness might misinterpret the effect of size on average returns. This can also explain why coskewness does not add much explanatory power to the model, but partially absorbs the effect of the loading on SMB.

A similar relationship is not detected for coskewness and book-to-market equity, irrespective of the measure of coskewness. This is in accordance with expectations, as the significance of the coefficient on the HML-loading is not as heavily affected by the implementation of coskewness in cross-sectional regressions. T-statistics of the beta-loadings are only marginally affected by the inclusion of coskewness, which means that beta still exhibits significant conditional and unconditional power in explaining the cross-section of real estate equity returns.

Although coskewness has no incremental or only marginal explanatory power over the loadings on the Fama-French factors in cross-sectional regressions, there is a strong indication that this measure of systematic risk should not be neglected in an asset-pricing framework. The crosssectional results provide evidence that coskewness is a priced risk factor and evokes an unconditional as well as a conditional effect on the pricing of risky real estate stocks.

\subsection{Robustness of Empirical Results}

To examine whether country, currency or weighting effects influence the results, a series of robustness checks is conducted. As country effects might exert the highest impact on the results, the effect is comprehensively examined. The data is augmented for each effect individually, and the time-series and cross-section regressions are rerun. For reasons of brevity, the tables are not reported, but can either be downloaded from the online appendix or requested from the authors.

\subsubsection{Country Effects}

Given that the average sizes and BE/MEs differ significantly across countries, the sorting procedure might result in some countries being predominantly in small/big or high/low BE/ME portfolios. Therefore, the portfolio returns, as well as SMB and HML could be influenced substantially by the performance of these countries. While the effect might be negligible for general equities (Bauer, Cosemans, Schotman 2010) and real estate equities (Schulte et al., 2011), this may not be the case for the impact of coskewness. Due to the inability to perform countryspecific asset pricing tests as a result of the small number of real estate stocks, the approach used is similar to that of Bauer et al. (2010) and Schulte et al. (2011). The size and BE/ME of each 
general and real estate company are regressed on country dummies. The monthly cross-section regressions take the form

$$
X_{i, m}=\pi_{m}+\sum_{j=1}^{J-1} \Pi_{j, m} C_{i, j}+\psi_{i, m}
$$

$\mathrm{m}=1,2, \ldots, 252$

$X_{i, m}$ is a vector containing the size or BE/ME of company $\mathrm{i}$ in month $\mathrm{t} . C_{i, j}$ is a dummy variable which is set to 1 if company $\mathrm{i}$ belongs to country $\mathrm{j}$ and 0 otherwise. The regression residuals $\psi_{i, m}$ measure company i's absolute size or BE/ME deviation from the country mean in month $\mathrm{m}$. In order to obtain relative deviations from the country's mean, the individual absolute size and $\mathrm{BE} / \mathrm{ME}$ deviations are divided by the average size or BE/ME of the respective country in month $\mathrm{m}$. The relative deviations are used subsequently to sort the real estate equities into 16 , and the general equities into six size-BE/ME portfolios, as described in Section 2.4. The approach ensures that only the largest/smallest and highest/lowest BE/ME companies, in terms of relative deviation from the respective mean and not by absolute value, are sorted into the respective portfolios. New portfolio returns, SMB and HML are derived and used in the subsequent analysis.

The returns on the equally-weighted portfolios excluding country effects are similar to those of the original model, as there seems to be a significant value effect. While the real estate value effect tends to become more accentuated, the value effect in the general stock market declines in magnitude. Moreover, SMB changes its sign for real estate equities and turns out to be negative (although insignificant). The returns on the 16 size-BE/ME portfolios yield a more irregular pattern, especially concerning the returns of the size portfolios for a given BE/ME portfolio. The returns on the six general equity portfolios follow the expected size-BE/ME pattern, except for the higher return on the big-growth-stock portfolio.

Compared to the original cross-sectional model of Equation (13a) and (14a) excluding coskewness, beta loses its unconditional explanatory power in the full sample when country effects are excluded. The loading on SMB is now priced when the financial crisis is excluded. In the conditional settings, the loading on SMB is much more significant for general equity and real estate up-markets and loses some of its power in down-markets, especially in the first sub-period. The loading on HML is now only significant in general equity down markets during the full and second sub-sample. However, this now implies higher returns in down-market states, which is in contrast to the earlier results. 
The effect of all four coskewness measures is much more pronounced than when country effects are not excluded. When conditioned on the general equity market, three measures exhibit significance in up-market states. This mostly stems from the first sub-period, in which all four proxies are significantly priced. There is also some evidence that coskewness is priced in downmarkets, especially when the financial crisis is excluded. The same applies when conditioning on the real estate up-market, for which three measures of coskewness exhibit significance in the full sample, excluding the financial crisis and in the first sub-sample. Regarding real estate downmarkets, coskewness is mostly priced when the financial crisis is excluded. All coefficients have the expected negative sign in up and positive sign in down-markets.

Similar to the base model, the inclusion of coskewness in the asset pricing test seems to capture some of the explanatory power of SMB. The loading on SMB becomes unconditionally significant in two cases and increases in significance during general equity up-markets in the first sub-sample. However, the significance declines considerably during down-markets. During general equity down-markets, this is especially the case for the first sub-sample and the full sample, while the same applies for real estate down-markets in the second sub-sample and the full sample. Moreover, the inconclusive coefficients regarding the loading on HML disappear once coskewness is included. Overall, the results support previous findings on the significance and impact of the FamaFrench factors and especially highlight the importance of coskewness in the pricing of European real estate equities.

\subsubsection{Currency Effects}

Using returns in one currency only, namely the Euro, assumes the position of an unhedged investor who is exposed to currency risk which might impact on the regression results.

Compared to the original model of Equation (13a) and (14a) excluding coskewness, beta loses its unconditional explanatory power in the full sample when returns are denominated in local currency. In the conditional settings, the loading on SMB is only (but more) significant in real estate up-markets and loses some of its power in general and real estate down-markets, especially in the first sub-period. The loading on HML is significant in all up and down-market states of the general and real estate market during the first sub-sample and also over the full sample, when the real estate market performs badly.

Similar to the model excluding country effects, the significance of all four coskewness measures is far higher than when returns are measured in Euros. One of the proxies for coskewness is priced 
unconditionally during the full sample, excluding the financial crisis and in the second sub-sample. When conditioned on the general equity market, all four measures exhibit significance in upmarket states. This stems mainly from the first sub-period, in which all four proxies are significantly priced and when the financial crisis is excluded, as indicated by two significant coefficients. There is also evidence that coskewness is priced in down-markets as all four measures are priced in the first sub-sample and two in the full sample. The same applies when conditioning on real estate up-market states, for which four measures of coskewness are significant during the full sample and excluding the financial crisis, as well as three in the second sub-sample. However, this contrasts with the results when country effects are excluded, as the pricing shifts from the first to the second sub-sample. Moreover, there is no evidence that coskewness is significantly priced in down-markets. All coefficients show the expected negative sign in up- and positive sign in down-markets.

Similar to the base model, the inclusion of coskewness in the asset pricing test seems to alter the pricing of the Fama-French factors. The loading on SMB seems to become slightly more significant when conditioned on the general equity market and during real estate up-markets. Concerning the general equity market, this is especially the case for the first sub-sample and when the financial crisis is excluded, while the same applies to real estate up-markets in the second subsample and excluding the financial crisis. The level of significance declines considerably during real estate down-markets for the second sub-sample and the full sample. However, the loading on HML seems to be more significant during such states, when the full sample and the sample excluding the financial crisis is considered. Overall, the previous findings are supported and do not seems to depend on the currency in which returns are denominated. However, the importance of coskewness seems to be much more pronounced in this case.

\subsubsection{Weighting Effects}

In order to ensure that the results do not depend on the return weighting, value-weighted instead of equally-weighted returns are used when calculating the market return, SMB and HML, as well as when performing the rolling time-series regressions.

Again, compared to the original model of Equation (13a) and (14a) excluding coskewness, beta loses its unconditional explanatory power in the full sample when value-weighted returns are used. In the conditional settings, the impact of the loading on SMB does not change fundamentally, except for general equity down-markets, where it is now insignificant during the first sub-sample, but significant in the full sample. The loading on HML is much more significant when conditioned 
on the real estate markets, as indicated by the considerably higher levels of significance, except for the first sub-sample in which the significance declines.

The evidence on the pricing of coskewness is mixed. None of the measures is significant in the unconditional pricing models. There seems to be some indication that coskewness is priced during general equity down-markets, at least when the financial crisis is excluded and during the first subsample. While one measure of coskewness is significant in real estate up-markets during the full and first sub-sample, the results suggest that coskewness is significantly priced during downmarkets in the first sub-sample, as indicated by four levels of significance. All coefficients have the expected negative sign in up- and positive sign in down-markets.

Similar to the base model, the inclusion of coskewness in the asset pricing test seems to alter the pricing of the Fama-French factors. Both the loadings on SMB and HML decline considerably in significance. Concerning the general equity down-markets, this is especially the case for the first sub-sample and the full sample. During real estate up-markets, the same applies for the full sample, excluding the financial crisis and the second sub-sample and especially for the loading on HML. The loading on SMB declines substantially in significance during real estate down-markets in all samples but the first sub-sample. Overall, the previous findings are supported and do not seem to depend on the weighting of returns. However, coskewness seems to be more important in this case, while being less important than in the other robustness checks.

\subsection{Conclusion}

Recent literature supports the explanatory power of coskewness in the pricing of risky assets. This paper is the first to address the question of whether coskewness can contribute to explaining European real estate equity returns. The Fama-French three-factor model is compared to a set of multi-factor models, which include four different measures of unconditional coskewness. The study covers 275 real estate equities from 16 European countries and spans the period from 1988 to 2009, as well as several subsamples. The asset pricing test is conducted by Fama-French (1993, 1996, 1997) time-series and Fama-MacBeth (1973) cross-section regressions. The cross-section regressions are conducted unconditionally as well as conditionally, following Pettengill et al. (1995, 2002), using positive or negative excess (general or real estate) equity market returns to distinguish between up- and down-market states. This study is the first to examine the role of coskewness in this conditional framework and therefore adds to a broader understanding of the pricing of coskewness in the cross-section of European real estate equity returns. 
The study highlights the importance of coskewness in the pricing of European real estate equities. In general, the findings reveal that assets which contribute negatively to the skewness of the broader equity market have, on average, higher returns than assets with higher coskewness. The results show that the inclusion of a quadratic market term does not yield incremental explanatory power over the Fama-French three-factor model in time-series regressions. In unconditional asset pricing tests, coskewness is the only priced factor besides beta. When conditioned on either the general or real estate equity market, both factors, as well as the sensitivities to SMB and HML are significant in explaining the cross-sectional variation in returns. Securities which contribute negatively to the skewness of the general equity market demand a higher premium in up and a lower premium in down-market states. Moreover, the results indicate that size and coskewness are related, as the inclusion of coskewness seems to alter the importance of SMB sensitivities in the pricing of real estate equities, especially in the condtional framework. However, the importance of coskewness seems to depend on the chosen proxy, as well as the time-period under examination. To validate the robustness of the results, the study controls for potential country, currency and weighting effects. While the main findings remain qualitatively unaltered, the results suggest that the impact of coskewness is more pronounced when the above-mentioned effects are controlled for. While the results support some findings from the US, such as Liu et al. (1992), they contradict Vines et al. (1994), Cheng (2005) as well as Yang and Chen (2009), who fail to detect a significant relationship between the cross-section of returns and co-/skewness. However, the results support Liow and Chan (2005), who suggest coskewness to be priced in various global real estate markets, including the Euro area.

The findings have important theoretical and practical implications, providing additional insight into the risk-return characteristics of European real estate equities. Failure to consider coskewness in asset pricing tests can lead to an inaccurate estimation of and compensation for bearing the additional risk involved. This is especially the case when distinguishing between up and downmarket states. Moreover, the omission of coskewness in asset pricing tests might lead to a biased estimation of the impact of SMB on asset returns. The results might help investors to improve their risk assessment and to perform time-varying investment strategies which consider coskewness risk. Further research could extend the model by including a Carhart (1997) momentum or a Pastor and Stambaugh (2003) liquidity factor. 


\section{References}

\section{References Real Estate Asset Pricing}

Anderson, R., Clayton, J., MacKinnon, G. \& Sharma, R. (2005). REIT Returns and Pricing: The Small Cap Value Stock Factor. Journal of Property Research, 22(4), 267-286.

Baca, S.P., Garbe, B.L. \& Weiss, R.A. (2000). The Rise of Sector Effects in Major Equity Markets. Financial Analysts Journal, 56(5), 34-40.

Banz, R.W. (1981), The Relationship Between Return and Market Value of Common Stocks. Journal of Financial Economics, 9, 3-18.

Barone-Adesi, G. (1985). Arbitrage equilibrium with skewed asset returns. Journal of Financial and Quantitative Analysis, 20(3), 299-313.

Barone-Adesi, G., Gagliardini, P. \& Urga, G. (2004). Testing Asset Pricing Models With Coskewness. Journal of Business and Economic Statistics, 22(4), 474-485.

Basu, S. (1977). Investment Performance of Common Stocks in Relation to Their Price-Earnings Ratios: A Test of the Efficient Market Hypothesis. The Journal of Finance, 32(3), 663-682.

Bauer, R., Cosemans, M. \& Schotman, P.C. (2010). Conditional Asset Pricing and Stock Market Anomalies in Europe. European Financial Management, 16(2), 165-190.

Bekaert, G., Hodrick, R.J. \& Zhang, X. (2009). International Stock Return Comovements. The Journal of Finance, 64(6), 2591-2626.

Bhandari, L.C. (1988). Debt/Equity Ratio and Expected Common Stock Returns: Empirical Evidence. The Journal of Finance, 43(2), 507-528.

Bond, S.A. \& Patel, K. (2003). The conditional distribution of real estate returns: Are higher moments time varying? Journal of Real Estate Finance and Economics, 26(2), 319-339.

Bond, S.A., Karolyi, G.A. \& Sanders, A.B. (2003). International real estate returns: a multifactor, multicountry approach. Real Estate Economics, 31(3), 481-500.

Cappiello, L., Kadareja, A. \& Manganelli, S. (2008). The Impact of the Euro on Equity Markets A Country and Sector Decomposition. Working Paper, European Central Bank, Frankfurt.

Carhart, M.M. (1997). On the Persistence in Mutual Fund Performance. The Journal of Finance, $52(1), 57-82$. 
Chan, K.C., Hendershott, P.H. \& Sanders, A.B. (1990). Risk and Return on Real Estate: Evidence from Equity REITs. AREUEA Journal, 18(4), 431-452.

Chen, S.-J., Hsieh, C.-H. \& Jordan, B.D. (1997). Real Estate and the Arbitrage Pricing Theory: Macrovariables vs. Derived Factors. Real Estate Economics, 25(3), 505-523.

Chen, S.-J., Hsieh, C., Vines, T.W. \& Chiou, S.-N. (1998). Macroeconomic Variables, FirmSpecific Variables and Returns to REITs. Journal of Real Estate Research, 16(3) 269-277.

Chen, N.-F., Roll, R. \& Ross, S.A. (1986). Economic Forces and the Stock Market. The Journal of Business, 59(3), 383-403.

Cheng, P. (2005). Asymmetric risk measures and real estate returns. Journal of Real Estate Finance and Economics, 30(1), 89-102.

Chiang, K.C.H., Kozhevnikov, K., Lee, M.-L. \& Wisen, C.H. (2006). REIT Mimicking Portfolio Analysis. International Real Estate Review, 9(1), 95-111.

Chiang, K.C.H., Lee, M.-L. \& Wisen, C.H. (2004). Another Look at the Asymmetric REIT-Beta Puzzle. Journal of Real Estate Research, 26(1), 25-42.

Chiang, K.C.H., Lee, M.-L. \& Wisen, C.H. (2005). On the Time-Series Properties of Real Estate Investment Trust Betas. Real Estate Economics, 33(2), 381-396.

Christie-David, R. \& Chaudhry, M. (2001). Coskewness and cokurtosis in futures markets. Journal of Empirical Finance, 8(1), 55-81.

Chui, A.C.W., Titman, S. \& Wei, K.C.J. (2003). The Cross-Section of Expected REIT Returns. Real Estate Economics, 31(3), pp. 451-479.

Chung, Y.P., Johnson, H. \& Schill, M.J. (2006). Asset Pricing When Returns Are Nonnormal: Fama-French Factors versus Higher-Order Systematic Comoments. Journal of Business, 79(2), 923-940.

Clayton, J. \& MacKinnon, G. (2003). The Relative Importance of Stock, Bond and Real Estate Factors in Explaining REIT Returns. Journal of Real Estate Finance and Economics, 27(1), 3960.

Cochrane, J.H. (2005). Asset Pricing. Princeton: Princeton University Press.

Conover, M.C., Friday, H.S. \& Howton, S.W. (2000). An Analysis of the Cross Section of Returns for EREITs Using a Varying-Risk Beta Model. Real Estate Economics, 28(1), 141-163. 
Daniel, K.D., Hirshleifer, D. \& Subrahmanyam, A. (2001). Overconfidence, Arbitrage, and Equilibrium Asset Pricing. The Journal of Finance, 56(3), 921-965.

Diacogiannis, G.P. (1994). Three-parameter asset pricing. Managerial and Decision Economics, 15(2), 149-158.

Eichholtz, P. \& Huisman, R. (2001). The Cross Section of Global Property Share Returns, Brown, S.J. and Liu, C.H. (Eds.). A Global Perspective on Real Estate Cycles, Kluwer Academic Publishers, Boston, 89-101.

Eichholtz, P., Huisman, R., Koedijk, K. \& Schuin, L. (1998). Continental Factors in International Real Estate Returns. Real Estate Economics, 26(3), 493-509.

EPRA (2010). Stock \& Index Snapshot. Market Capitalization and Number of Stocks of the EPRA/NAREIT Europe and United States Index", available at: http://www.epra.com/indices_matrix.jsp (accessed 30 October 2010).

Ewing, B.T. \& Payne, J.E. (2005). The response of real estate investment trust returns to macroeconomic shocks. Journal of Business Research, 58, 293-300.

Fama, E.F. \& French, K.R. (1992). The Cross-Section of Expected Stock Returns. The Journal of Finance, 47(2), 427-465.

Fama, E.F. \& French, K.R. (1993). Common Risk Factors in the Returns on Stocks and Bonds. Journal of Financial Economics, 33, 3-56.

Fama, E.F. \& French, K.R. (1996). Multifactor Explanations of Asset Pricing Anomalies. The Journal of Finance, 51(1), 55-84.

Fama, E.F. \& French, K.R. (1997). Industry cost of equity. Journal of Financial Economics, 43(2), 153-193.

Fama, E.F. \& French, K.R. (1998). Value versus Growth: The International Evidence. The Journal of Finance, 53(6), 1975-1999.

Fama, E.F. \& French, K.R. (2006). The Value Premium and the CAPM. The Journal of Finance, 61(5), 2163-2185.

Fama, E.F. \& MacBeth, J.D. (1973). Risk, Return, and Equilibrium: Empirical Tests. Journal of Political Economy, 81(3), 607-636.

Fang, H. \& Lai, T.-Y. (1997). Co-kurtosis and capital asset pricing. Financial Review, 32(2), 293. 
Fletcher, J. (1997). An Examination of the Cross-Sectional Relationship of Beta and Return: UK Evidence. Journal of Economics and Business, 49(3), 211-221.

Fletcher, J. (2000). On the conditional relationship between beta and return in international stock markets. International Review of Financial Analysis, 9(3), 235-245.

Ferreira, M.A. \& Gama, P.M. (2005). Have World, Country, and Industry Risks Changed in Time? An Investigation of the Volatility of Developed Stock Markets. The Journal of Financial and Quantitative Analysis, 40(1), 195-222.

Fraser, P., Hamelink, F., Hoesli, M. \& MacGregor, B. (2004). Time-varying betas and the crosssectional return-risk relation: evidence from the UK. The European Journal of Finance, 10(4), 255-276.

Fratzscher, M. (2002). Financial Market Integration in Europe: On the Effects of EMU on Stock Markets. International Journal of Finance and Economics, 7(3), 165-193.

Friend, I. \& Westerfield, R. (1980). Co-Skewness and Capital Asset Pricing. The Journal of Finance, 35(4), 897-913.

Galagedera, D.U.A. \& Brooks, R.D. (2007). Is co-skewness a better measure of risk in the downside than downside beta? Evidence in emerging market data. Journal of Multinational Financial Management, 17(3), 214-230.

Galagedera, D.U.A., Henry, D. \& Silvapulle, P. (2003). Empirical Evidence on the Conditional Relation between Higher-Order Systematic Co-moments and Security Returns. Quarterly Journal of Business and Economics, 42(1/2), 121-137.

Glascock, J.L., Lu, C. \& So, R.W. (2006). Excess Return and Risk Characteristics of Asian Exchange Listed Real Estate. Working Paper SSRN, 8 June 2006.

Griffin, J.M. (2002). Are the Fama and French Factors Global or Country Specific? Review of Financial Studies, 15(3), 783-803.

Guedhami, O. \& Sy, O. (2005). Does conditional market skewness resolve the puzzling market risk-return relationship? The Quarterly Review of Economics and Finance, 45(4-5), 582-598.

Hamelink, F. \& Hoesli, M. (2004). What Factors Determine International Real Estate Security Returns? Real Estate Economics, 32(3), 437-462.

Hardouvelis, G.A., Malliaropulos, D. \& Priestley, R. (2006). EMU and European Stock Market Integration. The Journal of Business, 79(1), 365-392. 
Harvey, C.R. (2000). Drivers of Expected Returns in International Markets. Emerging Markets Quarterly, 1-17.

Harvey, C.R. \& Siddique, A. (2000). Conditional Skewness in Asset Pricing Tests. The Journal of Finance, 55(3), 1263-1295.

Heston, S.L., Rouwenhorst, K.G. \& Wessels, R.E. (1999). The role of beta and size in the crosssection of European stock returns. European Financial Management, 5(1), 9-27.

Howe, J.S. \& Shilling, J.D. (1990). REIT Advisor Performance. AREUEA Journal, 18(4), 479500.

Howton, S.W. \& Peterson, D.R. (1998). An Examination of Cross-Sectional Realized Stock Returns using a Varying-Risk Beta Model. Financial Review, 33, 199-212.

Huang, P. \& Hueng, C.J. (2008). Conditional risk-return relationship in a time-varying beta model. Quantitative Finance, 8(4), 381-390.

Hung, C.-H. (2007). The Four-Moment CAPM and Non-Linear Market Models in Momentum and Size Strategies. Working Paper, Durham Business School, Durham.

Hung, D.C.-H., Shackleton, M. \& Xu, X. (2004). CAPM, Higher Co-moment and Factor Models of UK Stock Returns. Journal of Business Finance \& Accounting, 31(1), 87-112.

Hwang, S. \& Satchell, S.E. (1999). Modelling emerging market risk premia using higher moments. International Journal of Finance \& Economics, 4(4), 271-296.

Ince, O.S. \& Porter, R.B. (2006). Individual equity return data from Thomson Datastream: Handle with care! Journal of Financial Research, 29(4), 463-479.

Ingersoll, J. (1975). Multidimensional security pricing. Journal of Financial and Quantitative Analysis, 10(5), 785-798.

Jegadeesh, N. \& Titman, S. (1993). Returns to Buying Winners and Selling Losers: Implications for Stock Market Efficiency. The Journal of Finance, 48(1), 65-91.

Jurczenko, E. \& Maillet, B. (2006). Multi-moment Asset Allocation and Pricing Model. New York: John Wiley and Sons.

Karolyi, G.A. \& Sanders, A.B. (1998). The Variation of Economic Risk Premiums in Real Estate Returns. Journal of Real Estate Finance and Economics, 17(3), 245-262.

Kovac, V. \& Lee, S. (2008). The specific risk of the UK real estate securities market. Journal of Property Investment and Finance, 26(5), 399-417. 
Kraus, A. \& Litzenberger, R.H. (1976). Skewness preference and the valuation of risk assets. The Journal of Finance, 31(4), 1085-1100.

Lee, A., Moy, R.L. \& Lee, C.F. (1996). A multivariate test of the covariance-co-skewness restriction for the three moment CAPM. Journal of Economics and Business, 48(5), 515-523.

Lee, C.L., Robinson, J. \& Reed, R. (2008a). Downside Beta and the Cross-Sectional Determinants of Listed Property Trust Returns. Journal of Real Estate Portfolio Management, 14(1), 49-62.

Lee, M.-L., Lee, M.-T. \& Chiang, K.C.H. (2008). Real Estate Risk Exposure of Equity Real Estate Investment Trusts. Journal of Real Estate Finance and Economics, 36(2), 165-181.

Lee, S. \& Stevenson, S. (2007). The substitutability of REITs and value stocks. Applied Financial Economics, 17(7), 541-557.

Liew, J. \& Vassalou, M. (2000). Can book-to-market, size and momentum be risk factors that predict economic growth? Journal of Financial Economics, 57(2), 221-245.

Lin, C.Y., Rahman, H. \& Yung, K. (2009). Investor Sentiment and REIT Returns. Journal of Real Estate Finance and Economics, 39(4), 450-471.

Lin, B.H. \& Wang, J.M.C. (2003). Systematic skewness in asset pricing: an empirical examination of the Taiwan stock market. Applied Economics, 35(17), 1877-1887.

Ling, D.C. \& Naranjo, A. (1997). Economic Risk Factors and Commercial Real Estate Returns. Journal of Real Estate Finance and Economics, 14(3), 283-307.

Ling, D.C. \& Naranjo, A. (2002). Commercial Real Estate Return Performance: A Cross-Country Analysis. Journal of Real Estate Finance and Economics, 24(1), 119-142.

Lintner, J. (1965). The valuation of risk assets and the selection of risky investments in stock portfolios and capital budgets. The Review of Economics and Statistics, 47(1), 13-37.

Liow, K.H. (1997). The historical performance of Singapore property stocks. Journal of Property Finance, 8(2), 111-125.

Liow, K.H. \& Sim, M.C. (2006). The Risk and Return Profile of Asian Real Estate Stocks. Pacific Rim Property Research Journal, 12(3), 283-310.

Liow, K.H. \& Chan, L. (2005). Co-skewness and Co-kurtosis in Global Real Estate Securities. Journal of Property Research, 22(2/3), 163-203.

Liu, C.H., Hartzell, D.J. \& Grissom, T.V. (1992). The Role of Co-Skewness in the Pricing of Real Estate. Journal of Real Estate Finance and Economics, 5(3), 299-319. 
Liu, C.H. \& Mei, J. (1992). The Predictability of Returns on Equity REITs and Their CoMovement with Other Assets. Journal of Real Estate Finance and Economics, 5(4), 401-418.

Lizieri, C. \& Satchell, S. (1997). Interactions between property and equity markets: an investigation of linkages in the United Kingdom 1972-1992. Journal of Real Estate Finance and Economics, 15(1), 11-26.

Lu, K.W. \& Mei, J.P. (1999). The return distributions of property shares in emerging markets. Journal of Real Estate Portfolio Management, 5(2), 145-160.

Malin, M. \& Veeraraghavan, M. (2004). On the Robustness of the Fama and French Multifactor Model: Evidence from France, Germany, and the United Kingdom. International Journal of Business and Economics, 3(2), 155-176.

Matysiak, G. \& Brown, G. (1997). A time-varying analysis of abnormal performance of UK property companies. Applied Financial Economics, 7(4), 367-377.

McIntosh, W., Liang, Y. \& Tomkins, D.L. (1991). An Examination of the Small-Firm Effect within the REIT Industry. Journal of Real Estate Research, 6 (1), 9-17.

Misirli, E.U. \& Alper, C.E. (2009). Drivers of expected returns in Istanbul stock exchange: FamaFrench factors and coskewness. Applied Economics, 41(20), 2619-2633.

Moerman, G.A. (2005). How Domestic is the Fama and French Three-Factor Model? An Application to the Euro Area. Working Paper, Erasmus Research Institute of Management, Rotterdam.

Morelli, D. (2007). Beta, size, book-to-market equity and returns: A study based on UK data. Journal of Multinational Financial Management, 17(3), 257-272.

Morelli, D. (2010). European capital market integration: An empirical study based on a European asset pricing model. Journal of International Financial Markets, Institutions and Money, 20(4), 363-375.

Myer, F.C.N. \& Webb, J.R. (1993). Return properties of equity REITs, common stocks, and commercial real estate: a comparison. Journal of Real Estate Research, 8(1), 87-106.

Myer, F.C.N. \& Webb, J.R. (1994). Statistical properties of returns: financial assets versus commercial real estate. Journal of Real Estate Finance and Economics, 8(3), 267-282.

Newey, W.K. \& West, K.D. (1987). A Simple, Positive-Definite, Heteroskedasticity and Autocorrelation Consistent Covariance Matrix. Econometrica, 55(3), 703-708. 
Nguyen, D. \& Puri, T.N. (2009). Higher-Order Systematic Comoments and Asset Pricing: New Evidence. The Financial Review, 44(3), 345-369.

Ooi, J. \& Liow, K.H. (2004). Risk-Adjusted Performance of Real Estate Stocks: Evidence from Developing Markets. Journal of Real Estate Research, 26(4), 371-395.

Ooi, J.T.L., Webb, J.R. \& Zhou, D. (2007). Extrapolation Theory and the Pricing of REIT Stocks. Journal of Real Estate Research, 29(1), 27-56.

Pastor, L. \& Stambaugh, R.F. (2003). Liquidity Risk and Expected Stock Returns. The Journal of Political Economy, 111(3), 642-685.

Peterson, J.D. \& Hsieh, C.-H. (1997). Do common risk factors in the returns on stocks and bonds explain returns on REITs? Real Estate Economics, 25(2), 321-345.

Pettengill, G.M., Sundaram, S. \& Mathur, I. (1995). The Conditional Relation between Beta and Returns. Journal of Financial \& Quantitative Analysis, 30(1), 101-116.

Pettengill, G.M., Sundaram, S. \& Mathur, I. (2002). Payment for Risk: Constant Beta Vs. DualBeta Models. The Financial Review, 37(2), 123-136.

Rosenberg, B., Reid, K. \& Lanstein, R. (1985). Persuasive evidence of market inefficiency. Journal of Portfolio Management, 11, 9-17.

Rubinstein, M.E. (1973). The Fundamental Theorem of Parameter-Preference Security Valuation. The Journal of Financial and Quantitative Analysis, 8(1), 61-69.

Schulte, K.-M., Dechant, T. \& Schaefers, W. (2011). Systematic Risk Factors in European Real Estate Equities. Journal of European Real Estate Research, 4(3), forthcoming.

Scott, R.C. \& Horvath, P.A. (1980). On the Direction of Preference for Moments of Higher Order than Variance. The Journal of Finance, 35(4), 915-919.

Serrano, C. \& Hoesli, M. (2007). Forecasting EREIT Returns. Journal of Portfolio Management, 13(4), 293-309.

Shanken, J. (1992). On the estimation of beta-pricing models. Review of Financial Studies, 5(1), $1-33$.

Shanken, J. \& Weinstein, M.I. (2006). Economic forces and the stock market revisited. Journal of Empirical Finance, 13(2), 129-144.

Sharpe, W.F. (1964). Capital asset prices: A theory of market equilibrium under conditions of risk. The Journal of Finance, 19(3), 425-442. 
Smith, D.R. (2007). Conditional coskewness and asset pricing. Journal of Empirical Finance, 14(1), 91-119.

Spyrou, S. \& Kassimatis, K. (2009). Time-variation in the value premium and the CAPM: evidence from European markets. Applied Financial Economics, 19(23), 1899-1914.

Stattman, D. (1980). Book values and stock returns. The Chicago MBA: A Journal of Selected Papers, 4, 25-45.

Stevenson, S. (2001). Evaluating the investment attributes and performance of property companies, Journal of Property Investment and Finance. 19(3), 251-266.

Swanson, Z., Theis, J. \& Casey, K.M. (2002). REIT Risk Premium Sensitivity and Interest Rates. Journal of Real Estate Finance and Economics, 24(3), 319-330.

Vines, T.W., Hsieh, C.-H. \& Hatem, J.J. (1994). The Role of Systematic Covariance and Coskewness in the Prcing of Real Estate: Evidence from Equity REITs. Journal of Real Estate Research, 9(4), 335-341.

White, H. (1980). A Heteroskedasticity-Consistent Covariance Matrix Estimator and a Direct Test for Heteroskedasticity. Econometrica. 48(4), 817-838.

Yang, C.-Y. \& Chen, M.-C. (2009). The Role of Co-Kurtosis in the Pricing of Real Estate. Journal of Real Estate Portfolio Management, 15(2), 185-195.

Young, M.S. (2008). Revisiting non-normal real estate return distributions by property type in the US. Journal of Real Estate Finance and Economics, 36(2), 233-248.

Young, M.S. \& Graff, R.A. (1995). Real estate is not normal: a fresh look at real estate return distributions. Journal of Real Estate Finance and Economics, 10(3), 225-259.

Young, M.S., Lee, S.L. \& Devaney, S.P. (2006). Non-normal real estate return distributions by property type in the UK. Journal of Property Research, 23(2), 109-133. 


\section{List of Tables and Figures}

\section{Paper 2}

Table 1: Statistics of returns on 16 real estate equity portfolios formed on size and BE/ME

Table 2: Statistics of returns on six general equity portfolios formed on size and BE/ME

Table 3: Time-series regression results on 16 portfolios

Table 4: Cross-section regression results

\section{Paper 2 Online Appendix}

Table 1: Sample countries

Table 2: Number of Real Estate Equities in 16 Portfolios Formed on Size and BE/ME

Table 3: Number of General Equities in Six Portfolios Formed on Size and BE/ME

Table 4: Returns and Characteristics of 16 Real Estate Equity Portfolios Formed on Size and BE/ME

Table 5: Characteristics and Returns of Six General Equity Portfolios Formed on Size and BE/ME

Table 6: Time-Series Regression Results on 16 Portfolios

Table 7: Time-Series Regression Results on 16 Portfolios

Table 8: Time-Series Regression Results on 16 Portfolios

Table 9: Returns and Characteristics of 16 Real Estate Equity Portfolios Formed on Size and BE/ME Excluding Country Effects

Table 10: Returns and Characteristics of Six General Equity Portfolios Formed on Size and BE/ME Excluding Country Effects

Table 11: Cross-Section Regression Results - Robustness Check Excluding Country Effects

Table 12: Cross-Section Regression Results - Robustness Check Using Returns in Local Currency

Table 13: Cross-Section Regression Results - Robustness Check Using Value-Weighted Returns 